\title{
LÍNGUA CULTA PADRÃO: UM INTERTEXTO ENTRE PODER E LUGAR SOCIAL
}

\author{
Vaima Regina Alves Motta
}

\section{RESUMO}

O presente artigo pretende apresentar reflexões sobre como o sistema escolar, através de uma das suas engrenagens, a Língua Culta Padrão, torna-se uma instituição que acaba fortalecendo a manutenção de certos lugares sociais. Sustenta-se em autores como Veblen, Pross, Berger \& Luckmann para pensar o homem como um ser constituído a partir de sua localização social e como a imagem que tem de si é capaz de Ihe impor limites ou rótulos. Em Homi Bhabha e Gregory Bateson encontram-se subsídios para refletir sobre relações sociais desiguais. Na produção de Bourdieu, buscam-se elementos que retratam a língua-padrão como instrumento de manutenção do poder, e a partir do cruzamento das teorias pesquisadas pretende-se enfatizar que um trabalho escolar com linguagem pode ter conseqüências sérias se for centrado na Língua Culta Padrão.

"A população colonizada é então tomada como a causa e o efeito do sistema, presa no círculo da interpretação".

Bhabha,1998.

\section{INTRODUÇÃO}

Seria ingenuidade pensar as relações escolares (professor e aluno) e os resultados cognitivos e de ascensão sócio-econômica insatisfatórias resultantes desse encontro, exclusivamente, como fruto de impropriedade metodológica, propostas de trabalho inadequadas ao contexto, número excessivo de alunos em sala de aula ou outros fatores de mesma natureza.

A reflexão teria um caráter falacioso, pois se estaria pontuando o princípio do problema sem considerar o processo histórico do qual essa instituição é fruto e construção. É como tratar os efeitos de um mal, desconsiderando completamente suas causas, uma fonte que se perpetua porque fortalece identidades e garante lugares sociais.

Pensar as dimensões desse alcance em poucas páginas acarretaria uma reflexão frágil e sem propósito, porém situar o universo que envolve individualidades e instituição escolar é imprescindível para refletir sobre o papel que a Língua Culta Padrão desempenha na continuidade histórica dos lugares sociais. 
No início apresentar-se-á reflexões sobre o papel que desempenha o meio social na constituição do "eu" e a situação de exclusão que podem ser resultantes dessa interferência. Em seguida, discute-se a instituição escolar como elemento determinante na constituição dos papéis sociais. Por último busca-se apresentar o trabalho com a Língua Culta Padrão como um dos mecanismos através dos qualis se promove a exclusão e se fortalece as diferenças sociais.

\section{O INDIVIDUAL E O SOCIAL: AS REGRAS DA DETERMINAÇÃO DO "EU"}

Berger \& Luckmann (1985) afirmam que "a sociologia do conhecimento compreende a realidade humana como uma realidade socialmente construída." (p.246). Dessa forma é impossível pensar a constituição do ser sem considerar os efeitos do entrelaçamento desse eu com o reconhecimento dele pela sociedade da qual é parte.

O sujeito individual apresenta-se como um ser cuja essência está predestinada a uma pseudo-originalidade, uma vez que dialeticamente homem e mundo passam a ser determinados pela aceitação social que determina um lugar para 0 sujeito, impingindo-lhe uma aceitação parcialmente inconsciente de uma posição resultante de ações reflexas. A questão primordial 'Quem sou eu?' não seria satisfatoriamente respondida sem a confirmação do meio. Sozinho, o indivíduo é incapaz de qualificar-se como sujeito, precisa da convivência social, como refletem Berger \& Luckmann (1985):

Para conservar a confiança de que é na verdade a pessoa que pensa que é, o indivíduo necessita não somente a confirmação implícita desta identidade, que mesmo os contatos diários casuais poderiam fornecer, mas a confirmação explícita e carregada de emoção que lhe é outorgada pelos outros significantes para ele. (p.200)

Por outro lado, o socialmente estabelecido também precisa ser reconhecido pelo individual, o que implica uma introspecção de modelos, limites, conceitos e outros, como ideais de referência que prefiguram uma idéia constituída de sociedade e, como registram Berger \& Luckmann (1985), "só existe quando os indivíduos têm consciência dela." (p.109)

Considerando, como afirma Marx (apud Veblen, 2003), "ser a consciência do homem determinada por seu papel social' (p.17), o 'eu' será estabelecido no lugar que objetiva e subjetivamente o construto social permitir, estabelecendo uma espécie de paradigma qualificador que tem o poder de inclusão ou exclusão. Dessa maneira o 'eu' será socialmente merecedor de reconhecimento se sua suposta herança histórica ou poder de façanha (Veblen, 2003) forem aprovados, caso contrário não será digno de fazer parte de um grupo.

Pross (1980) reflete com muita propriedade sobre essa questão:

A segregação social se realiza mediante marcas, estigmas, enegrecimentos, cortes a certos signos similares, que menosprezam a dignidade humana do sujeito, ao criar imagens que não guardam proporção com as correntes e 
que, portanto, repelem. Também, a distinção de indivíduos ou grupos particulares se faz mediante uma etiquetação.(p.105)

Viver alheio a essa espécie de "etiquetação" é quase impossível. Veblen (1980) registra que "somente os indivíduos de temperamento excepcional conseguem, diante da reprovação da comunidade, conservar em última análise a própria auto-estima" (p.29). Assim, realizar-se como indivíduo depende dessa possibilidade de fazer-se parte de um todo e descobrir que o papel que desempenha na sociedade merece respeito e tem reconhecido valor. Caso contrário, a exclusão do 'eu' é reconhecida pelo próprio indivíduo como lógica.

Sobre essa questão de exclusão e auto-exclusão, Elias \& Scotson (2000), na obra 'Os estabelecidos e os outsiders', resultado de uma pesquisa de campo que serviu como laboratório para analisar problemas de exclusão, discutem como é possível um estigma social interferir na auto-imagem de alguém ou de um grupo, enfraquecendo-o a ponto desse acreditar-se de "valor humano inferior".

Essa constatação tem respaldo nas afirmações de Berger \& Luckmann (1985) quando escrevem que "... não há pensamento humano que seja imune às influências ideologizantes de seu contexto social' (p.22), e isso acaba demarcando limites para os investimentos individuais, pois define a auto-imagem, atrelando sua autoconsciência a um estigma exterior.

A partir dessas reflexões, seria possível pensar sobre a participação da escola em todo esse processo e nos reflexos dessa existência na constituição do sujeito.

\section{ESCOLA: INSTRUMENTO DE PODER}

A escola como instituição social reproduz ao longo do tempo e garante a manutenção de lugares estabelecidos, agindo como célula responsável por determinar a continuidade das representações de poder, mesmo que o não faça de forma totalmente intencional.

As ações escolarizadas são resultados de práticas circulares e temporais que vão reafirmando um sistema de exclusão e transformando os envolvidos nesse processo em uma espécie de colonizadores acéfalos (professores) e colonizados conformados (alunos). Berger \& Luckmann (1985) sustentam esse caráter histórico da escola quando refletem que:

As instituições implicam (...) a historicidade e o controle. As tipificações recíprocas das ações são construídas no curso de uma história compartilhada. Não podem ser criadas instantaneamente. As instituições têm sempre uma história, da qual são produtos. (p. 79)

Sob essa linha reflexiva é possível pensar a escola como o órgão oficial de manutenção do poder, cujas engrenagens mantêm, ao longo dos anos, um sistema capaz de estabelecer lugares sociais definidos. Toda estrutura organizacional da escola contribui para este fim, uma vez que se apresenta quase inal- 
terada, apesar de tantas mudanças fora dela. A escola representa um "totemismo às avessas" em relação ao 'eu', pois impõe-se como indispensável e vantajoso mas promove a manutenção do poder cujo efeito é a exclusão daqueles que mais precisam dela.

Sobre a autoridade delegada à escola, Bourdieu (1996) escreve:

\begin{abstract}
O sistema escolar dispõe da autoridade necessária para exercer universalmente uma ação de inculcação duradoura em matéria de linguagem, tendendo assim a proporcionar a duração e a intensidade desta ação ao capital cultural herdado. (p.50)
\end{abstract}

Quando discute as relações pós-colonialistas, Bhabha (1998) analisa a questão da manutenção de papéis como algo intencionalmente construído. Quem é a pessoa que fala? O lugar social de onde oraliza sua voz confunde-se com 0 próprio 'eu' e determina o nível de importância dessa voz:

O que se interroga não é simplesmente a imagem da pessoa, mas o lugar discursivo e disciplinar de onde as questões de identidade são estratégica e institucionalmente colocadas. ( p.81)

Assim, escola e alunos estariam envolvidos em uma relação complementar (Bateson,1999), aparentemente tranqüila, mas que promove a anulação de uma das partes, no caso, anulação do aluno por parte do sistema escolar e anulação do professor pelo sistema maior, situando-os em lugares de impossibilidades.

Bhabha (1998) fala de "objeto de desejo e escárnio" - a escola, por sua vez, também pode ser lida através desta lente, já que personifica ao mesmo tempo possibilidades e impossibilidades da ocupação dos lugares sociais. È um rito de passagem que transforma o porta-voz do sistema, o professor, em um capataz através da avaliação, classificação e, principalmente, através da busca pelo uso da Língua Culta Padrão.

\title{
4. LÍNGUA CULTA PADRÃO: UMA VARIANTE DE EXCLUSÃO
}

Discute-se atualmente que um dos compromissos da escola é promover o acesso à competência comunicativa ( Widdowson, 1991), que supostamente garantiria ao aluno avançar a um patamar superior. Contudo, ao pensar a linguagem trabalhada na escola como um patrimônio nacional, é difícil concebê-la como um meio de ascensão a privilégios, pois situa-se como parcela integrante da instituição escolar, e esta, como foi discutido anteriormente, é reflexo da história de manutenção de lugares e de poder.

Bourdieu (1996) refere-se à língua-padrão como algo abstrato e desta forma sem função emancipatória, mas, sim, subserviente a um sistema:

...quando surgem usos e funções inéditos motivados pela constituição da nação, entidade inteiramente abstrata e fundada no direito, tornam-se indispensáveis a língua-padrão, tão impessoal e anônima como os usos oficiais a 
que ela se presta e, ao mesmo tempo, o trabalho de normalização dos produtos dos habitus lingüísticos. ( p.34)

Esmiuçando o léxico "abstrato", encontra-se como designação (Larousse,1992) "intangível,estado abstraído dos seres a que pertencem" (p.8). A partir dessa explicitação, a Língua Culta Padrão (LPC) não pode ser alcançada pelo 'eu' comum, se considerada sua essência (não se está pontuando, aqui, "abstrato" numa leitura saussureana) ou a função que desempenha no sistema social.

Seu caráter abstrato não facilita, mas fortalece diferenças e impõe limites entre o poder instituído e os indivíduos comuns. A reflexão de Bourdieu (1996) sobre língua legítima $X$ expressões populares ilustra com adequação a relação de imposição que se estabelece entre as extremidades da escala social:

\begin{abstract}
A imposição da língua legítima contra os idiomas e os dialetos fazem parte das estratégias políticas destinadas a assegurar a eternização das conquistas da revolução pela produção e reprodução do homem novo. Ao fazer da língua um método, a teoria de Condillac permite identificar a língua revolucionária com o pensamento revolucionário: reformar a língua, expurgá-la dos usos ligados à antiga sociedade e impô-la assim purificada é o mesmo que impor um pensamento igualmente depurado e purificado. Seria um tanto ingênuo atribuir a política de unificação lingüística apenas às necessidades de comunicação entre diferentes partes do território... (p.34)
\end{abstract}

Os professores, por sua vez, tornam-se facilitadores oficias da manutenção do status quo. Berger \& Luckmann (1985) os definem como "funcionários institucionais, com a atribuição formal de transmitir conhecimentos específicos" (p.189). Essa posição, reflexo histórico, transforma a ação docente, no que diz respeito ao trabalho com LCP, no maior instrumento de exclusão. Ele desmerece outras formas de expressão, é hermética e infrutífera se trabalhada com o fim em si mesma ou, ainda, com o propósito de determinar o ideal a ser promovido pela escola.

A impossibilidade de domínio da LCP e a falta de objetivo para esse domínio informam o suposto "valor inferior" e o "lugar secundário" do aluno pertencente às classes populares, estabelecendo o intertexto perfeito entre poder e escola.

O indivíduo é capaz de se comunicar ao longo da vida, mas a LCP, institucionalmente apresentada pela escola, não é ponte que favorece o crescimento pessoal, é limite. Qualifica-o como ser menor, o que repercute nas suas próprias relações sociais como afirmam Berger \& Luckmann (1985): "Minha participação com os outros na vida cotidiana é, por conseguinte, constantemente afetada por nossa participação comum no acervo social disponível do conhecimento" (p.62).

Se o professor pensar seu lugar social, também como reflexo histórico e entender que a exclusão de todos os envolvidos no sistema escolar, seja do aluno ou dele próprio, dá-se pela aceitação de papéis sociais cujos limites muitas vezes são frágeis e pouco claros, poderá principiar uma tentativa de ruptura nesse processo cíclico. Muitos são os pontos nevrálgicos que se sedimentam como mantenedores do poder, a LCP é só mais um elemento de todo o sistema, porém forte o suficiente para transformar-se em uma guilhotina. Por isso, ser ma- 
nipulada de forma impensada pelo professor representará bem mais do que mera ingenuidade.

\section{CONSIDERAÇÕES FINAIS}

Quando se pensa a Língua culta padrão dentro de um contexto sócio-histórico, é possível entender o quanto sutil pode ser a relação entre constituição individual e sociedade.

A Língua Culta Padrão é utópica, distante da realidade e sem função prática. Por isso, as escolas cujo modelo de trabalho privilegia esse tipo de linguagem tornam-se instrumentos de exclusão a serviço de um processo histórico que fortalece a possibilidade de alguns, da mesma forma que acaba reforçando a impossibilidade de outros, menos favorecidos socialmente.

A escola, dessa forma, acaba tornando-se um dos meios para a instituição de lugares sociais, os quais interferem na auto-imagem do sujeito e, assim, na própria constituição do "eu".

Portanto, é também tarefa do professor entender os efeitos nocivos dessas relações de manutenção do poder e reavaliar a importância e o alcance que pode ter o trabalho com linguagem em sala de aula. Redefinir parâmetros seria um bom começo.

\section{BIBLIOGRAFIA}

BERGER, Peter L.: LUCKMANN, Thomas. A construção Social da Realidade. Petrópolis: Vozes,1985.

BHABHA, Homi. O Local da Cultura. Belo Horizonte: Ed.UFMG, 2003.

BATESON, Gregory. Steps to an ecology of mind. Chicago: Chicago Press, 1999.

BOURDIEU, Pierre. A Economia das Trocas lingüísticas. São Paulo: EDUSP.1996.

ELIAS, Norbert: SCOTSON, John L. Os Estabelecidos e os Outsiders. Rio de Janeiro: Jorge Ahar, 2000.

LAROUSSE. Dicionário da Língua Portuguesa. São Paulo: Editora Nova Cultura, 1992.

PROSS, Harry. Estrutura Simbolica del Poder. Barcelona: Editorial Gustavo Gili, 1980 .

VEBLEN, Thordike B. A Teoria da Classe Ociosa In: Veblen, Thordike. Os pensadores. São Paulo: Abril Cultural, 2003.

WIDDOWSON, H. G. O Ensino de Línguas para a Comunicação. Campinas: Pontes, 1991. 